\title{
Evaluation of Antioxidant Prophylactic Effects of Parsley (Petroselinum Crispum) on Sepsis Following Cecal Ligation and Puncture
}

Yasir Furkan Cagin ( $\nabla$ yafur@hotmail.com )

Inonu University Faculty of Medicine https://orcid.org/0000-0002-2538-857X

Ihsan Kulaksiz

Istanbul Universitesy

Nigar Vardi

Inonu Universitesi Tip fakultesi

Hakan Parlakpinar

Inonu University, Faculty of Medicine, Department of Medical Pharmacology, Malatya, Turkey

Onural Ozhan

Inonu Universitesi Tip fakultesi

Azibe Yildiz

Inonu Universitesi Tip fakultesi

Alaadin Polat

Inonu Universitesi Tip fakultesi

Kevser Tanbek

Inonu Universitesi Tip fakultesi

Ahmet Kadir Arslan

Inonu Universitesi Tip fakultesi

\section{Research Article}

Keywords: Oxidative stress, parsley, Petroselinum crispum, phytotherapy, rat, sepsis

Posted Date: August 4th, 2021

DOI: https://doi.org/10.21203/rs.3.rs-751422/v1

License: (c) (i) This work is licensed under a Creative Commons Attribution 4.0 International License.

Read Full License 


\section{Abstract}

Background and Aims. Sepsis causes release of free oxygen radicals that destroy membrane integrity.We evaluated the antioxidant effects of parsley, Petroselinum crispum( $P c)$, which has been used therapeutically for centuries in Anatolia, using a rat model of sepsis caused by cecal ligation and puncture (CLP).

Methods.Wistar albino rats were separated into four groups of eight: a sham group with incised and sutured abdomen, a Pc extract(PcE) group was given $2 \mathrm{~g} / \mathrm{kg}$ parsley extract for 14 days by gastric gavage, a CLP group with sepsis caused by CLP and a PcE + CLP group given parsley extract for 14 days, then made septic by CLP. PcE is given for 14 days and then sepsis is performed by the CLP procedure.

Results. The groups were compared in terms of hemogram, biochemical and histological characteristics. It has been proven that the administration of PcE before CLP-induced sepsis increases neutrophil, PLT counts and TAS levels which decrease with sepsis and decreases biochemical changes (BUN, AST, ALT, $\mathrm{LDH}, \mathrm{TOS}, \mathrm{OSI}$ ) which increase with sepsis, to have a protective effect on sepsis. In the PcE + CLP group, the severity of intestinal infiltration was decreased significantly compared to the CLP group; epithelial damage was similar to the CLP group. In the PcE + CLP group, the crypt and villus length was greater and the decrease in Paneth cell degranulation intensity was found to be more than for the CLP group ; also, the morphology of the cells was similar to the Sham group.

Discussion. PcE exhibit potential for prophylaxis for sepsis.

\section{Introduction}

Sepsis is an irregular and excessive systemic inflammatory response to an infection. Despite improving treatments, it has a high mortality rate and requires early intervention [1]. The mortality rate for sepsis is approximately $30 \%$; mortality increases as it develops from severe sepsis to septic shock and multiple organ failure syndromes [2].

One factors contributing to the pathogenesis of sepsis is excess production of free oxygen radicals. Mitochondria are most susceptible to damage by oxidation. The release of free oxygen radicals eliminates membrane potential and disrupts membrane integrity [3-5].

Cecal ligation and puncture (CLP) in rats mimic the characteristics and course of clinical sepsis [6]. The CLP model can be used to vary the severity of sepsis by controlling the size of the perforation [7].

Petroselinum crispum, known also as parsley, can be grown almost anywhere and has been used traditionally for treatment of many maladies. Apigenin, cosmosiin oxypeucedanin hydrate, myristicin, apiol, cnidil and apiin have been detected in the aqueous extract of Petroselinum crispum leaves. Also, coumarins, carotenoids and other compounds occur in various parts of the parsley plant [8]. Some compounds in parsley exhibit antioxidant properties [9]. 
We investigated the protective effects of Petroselinum crispum extract by preventing formation of free oxygen radicals and oxidative stress due to sepsis.

\section{Material And Methods}

\section{Animals}

The Ethics Committee for Experimental Animal Research approved our study (Reference no. 2015/A-34). Our study was performed according to the principles of Animal Research Guideline of International Health Board in the laboratory of Experimental Animal Production (EAP) with the permission of The Ethics Committee of Experimental Animals. We used 32 180-220 g female Wistar albino rats obtained from EAP Center. Rats were housed at $21 \pm 2{ }^{\circ} \mathrm{C}, 60 \pm 5 \%$ humidity with a $12 \mathrm{~h}$ light: $12 \mathrm{~h}$ dark cycle. Before the experiment, rats provided standard feed and water ad libitum.

\section{CLP}

The sepsis model was created by CLP. A $1 \mathrm{~cm}$ midline incision was made in the abdominal wall under anesthesia. The cecum was exposed and ligated with a $4-0$ silk suture, then punctured twice with a 22 gauge needle. A small amount of fecal content was released by gentle squeezing of the cecum then repositioned with a 4 - 0 silk suture. After the procedure, $1 \mathrm{ml}$ saline solution(SS) was administered subcutaneously to the animals in each group. After sepsis symptoms including lethargy, fever, piloerection and diarrhea were observed after $24 \mathrm{~h}$, animals were euthanized, by bleeding after a $5 \mathrm{ml}$ blood sample was collected from the inferior vena cava and the experiment was terminated [10] .

\section{Experimental design}

The rats were allocated to our groups of eight. 1) Sham operated group. 2) Petroselinum crispum extract (PcE) group; $2 \mathrm{~g} / \mathrm{kg}$ PcE was administered once daily for 14 days by orogastric gavage. 3) CLP group. 4) PcE + CLP group; after application of $2 \mathrm{~g} / \mathrm{kg}$ gavage once daily PcE for 14 days, rats were made septic by CLP.

\section{Tissue samples}

On day 15 , under anesthesia with $100 \mathrm{mg} / \mathrm{kg}$ ketamine and $10 \mathrm{mg} / \mathrm{kg}$ xylazine, the skin was shaved and sterilized with iodine and laparotomy was performed. Rats were sacrificed by extracting $5 \mathrm{ml}$ blood from the inferior vena cava $24 \mathrm{~h}$ after CLP. Characteristics measured included a hemogram, LDH, AST, ALT, BUN, creatinine, glucose, bicarbonate, CRP and ASO. A $10 \mathrm{~cm}$ portion intestinal tissue samples from the ascending colon including the cecum was placed in $10 \%$ formol for histopathological examination; the remaining portion was frozen in liquid nitrogen and stored in a $-35^{\circ} \mathrm{C}$ freezer until biochemical measurements. Two hundred milligrams of frozen tissue specimens cut into pieces on dry ice was homogenised in PBS buffer $(1: 9, \mathrm{w} / \mathrm{v})$ using a manual glass homogeniser for approximately 5 min and flushed with centrifugation $3500 \mathrm{~g} \times 45$ minutes for approximately to remove large debris. The supernatant was used for TAS and TOS analysis. 


\section{Total antioxidant status (TAS)}

TAS was measured using the automated colorimetric measurement method Biotek Synergy HT plate reader immunostimulant gene 5-software and kit Rel Assay (Rel Assay Diagnostics kit, Mega Tip, Gaziantep, Turkey) developed by Erel [11]. The hydroxyl radical is produced by the Fenton reaction and reacts with the colorless substrate, 0-dianisidine, to produce the dianisyl radical, which is bright yellowish brown. Upon the addition of tissue samples, the oxidative reactions initiated by the hydroxyl radicals in the reaction mix are suppressed by the antioxidant components of the sample, which prevents the color change to provide a measure of the total antioxidant capacity of the example. The antioxidants in the sample opening the color in proportion to their concentration. The reaction can be monitored spectrophotometrically, and the opening ratio in color is proportional to TAS for the sample. The assay is calibrated with a stable antioxidant standard solution which is traditionally named as Trolox Equivalent that is a vitamin E analog. Results were expressed as mmol Trolox Equiv/ L.

\section{Total oxidant status (TOS)}

TOS measurement was performed using a TOS Biotek Synergy HT plate reader immunostimulant gene 5software and kit Rel Assay (Rel Assay Diagnostics kit, Mega Tip, Gaziantep, Turkey) developed by Erel. Oxidants in the tissue samples oxidize the ferrous ion-0-dianisidine complex to ferric ion. The oxidation reaction is enhanced by glycerol molecules in the reaction medium. The ferric iron produces a colored compound with chromogen in an acidic medium. This chromogen is orange and reagent. The assay kit is calibrated like this. The color intensity, which can be measured spectrophotometrically, is related to the total amount of oxidant molecules present in the sample. The assay was calibrated using $\mathrm{H}_{2} \mathrm{O}_{2}$ and the results were expressed $\mu \mathrm{mol} \mathrm{H}_{2} \mathrm{O}_{2}$ equiv/l .

\section{Oxidative stress index (OSI)}

The percent ratio of the TOS to the TAS gave the oxidative stress index (OSI), an indicator of the degree of oxidative stress $[12,13]$. To perform the calculation, the result unit of TAS, mmol Trolox equivalent/L, was converted to $\mu \mathrm{mol}$ equivalent/L and the OSI value was calculated as below formula;

OSI (arbitrary unit) $=[($ TOS, $\mu \mathrm{mol} / \mathrm{I}) /($ TAS, mmol Trolox equivalent $/ \mathrm{l}) \times 100]$.

\section{Histology}

Tissue samples were fixed with $10 \%$ formaldehyde. After the tissue follow-up procedures, dehydrated through $80,95 \%$ and absolute ethyl alcohol, cleared in xylene, embedded in paraffin, and the tissue sections were taken from paraffin blocks sections were cut at 4-5 $\mu \mathrm{m}$. Sections were deparaffinized, rehydrated and stained with hematoxylin and eosin $(\mathrm{H} \& \mathrm{E})[14]$ for examination of morphology. Sections of intestinal mucosa were examined in terms of epithelial spillage and mononuclear cell infiltration. Alterations in structure were evaluated using a semi-quantitative method according to the following scale: 0 (absent), 1 (mild), 2 (moderate), and 3 (severe)[15] 20 villus and crypt lengths were measured in each section. Also, 100 Paneth cells/section were evaluated for degree of degranulation[16]. Analyses were 
performed using the Leica Q Win Image Analysis System (Leica Micros Imaging Solutions Ltd., Cambridge, UK) with a Leica DFC-280 research microscope.

\section{Immunohistochemistry}

After deparaffinization and rehydration, sections were placed in citrate buffer, $\mathrm{pH} 6.0$, antigen retrieval solution and boiled in a pressure cooker for $20 \mathrm{~min}$. Then the sections were washed with phosphatebuffered saline (PBS). After washing, $3 \%$ hydrogen peroxide solution was applied to block endogenous peroxide for $12 \mathrm{~min}$ at room temperature, then washed with PBS. Protein blocker was applied to the sections to prevent nonspecific background staining. The sections were incubated with caspase-3 primary antibody (rabbit polyclonal; Thermo Fisher Scientific, Anatomical Pathology, Fremont, USA) for 60 min, then rinsed with PBS, incubated with biotinylated goat anti-polyvalent for 10 min and streptavidin-peroxidase for $10 \mathrm{~min}$ at room temperature. Staining was completed with chromogen (AEC Substrate System; AEC Chromogen ad AEC Substrate, add $20 \mu$ of AEC Chromogen to $1 \mathrm{ml}$ of AEC Substrate) (Thermo Fisher Scientific, Anatomical Pathology, Fremont, USA) + substrate for 10 min followed by counterstaining with Mayer's hematoxylin for $1 \mathrm{~min}$, rinsing in tap water and dehydration. Caspase-3 positive cells were stained brown.

According to the prevalence of the staining, the sections were graded as $1=0-25 \%$ staining; $2=26-50 \%$ staining; $3=$ staining $51-75 \% ; 4=$ staining $76-100 \%$. According to the staining intensity, the sections were graded as follows: 0 = no staining; 1 = weak but detectable staining; $2=$ distinct; $3=$ intense staining.

Total staining score was obtained as (prevalence)X(intensity)[17]. All sections were evaluated using a Leica DFC280 light microscope and a Leica Q Win Image Analysis system (Leica Micros Imaging Solutions Ltd., Cambridge, UK).

\section{Statistical analysis.}

IBM SPSS statistics version 17.0 for Windows was used for statistical analyses. Normally distributed data were analyzed by ANOVA (Tamhane) test. For data not showing normal distribution, the comparison between groups was performed with the Kruskal-Wallis $\mathrm{H}$ test. After Kruskal-Wallis $\mathrm{H}$ test, multiple comparisons were made by Conover test. The results were expressed as median (minimum-maximum) and mean \pm standard deviation. Values for $p \leq 0.05$ were considered statistically significant.

\section{Results}

\section{Biochemistry}

A significant increase was detected in the Hb, lymphocytes, neutrophils, BUN, Crea, ALT, AST and LDH levels between CLP, PcE + CLP groups and Sham group $(P<0.05)$, but no significant difference was observed between CLP and PCE + CLP groups(Table 1). 
Table 1

Comparison of the Serum Hemogram and Biochemistry Parameters among the Study Groups

\begin{tabular}{|c|c|c|c|c|c|}
\hline \multirow[t]{2}{*}{ Parameters } & \multicolumn{4}{|l|}{ Groups } & \multirow{2}{*}{$\begin{array}{l}\mathrm{p}- \\
\text { value }\end{array}$} \\
\hline & Sham & PcE & CLP & $\mathrm{PcE}+\mathrm{CLP}$ & \\
\hline 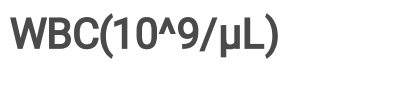 & $\begin{array}{l}5.69(2.31- \\
9.92)\end{array}$ & $\begin{array}{l}6.35(3.71- \\
14.04)\end{array}$ & $\begin{array}{l}4.09(3.26- \\
9.76)\end{array}$ & $\begin{array}{l}4.36(2.36- \\
10.03)\end{array}$ & 0.4073 \\
\hline $\mathrm{HGB}(\mathrm{g} / \mathrm{dL})$ & $\begin{array}{l}15.9(13.9- \\
18.4)\end{array}$ & $\begin{array}{l}15.1^{\mathrm{b}}(14.1- \\
16)\end{array}$ & $\begin{array}{l}18.7^{\mathrm{c}}(14.7- \\
20.9)\end{array}$ & $\begin{array}{l}14.55(13.3- \\
18.2)\end{array}$ & 0.0301 \\
\hline $\operatorname{LY}(\%)$ & $\begin{array}{l}64^{b . c}(35.4- \\
71.9)\end{array}$ & $\begin{array}{l}64.7^{\text {b.c }}(31.8- \\
85.2)\end{array}$ & $\begin{array}{l}21.3(14.7- \\
40.3)\end{array}$ & $\begin{array}{l}20.8(10- \\
41.7)\end{array}$ & 0.0002 \\
\hline $\mathrm{MO}(\%)$ & $\begin{array}{l}4.6^{\mathrm{b}}\left(3.5^{-}\right. \\
8.9)\end{array}$ & $\begin{array}{l}3.4^{\text {b.c }}(2.6- \\
23.2)\end{array}$ & $\begin{array}{l}9.4(5.5- \\
46.2)\end{array}$ & $\begin{array}{l}18.05(2.8- \\
32)\end{array}$ & 0.015 \\
\hline $\mathrm{NE}(\%)$ & $\begin{array}{l}31.2^{\text {b.c }} \\
(24.6-55.3)\end{array}$ & $\begin{array}{l}31.6^{\text {b.c }}(11.8- \\
50.1)\end{array}$ & $\begin{array}{l}49.9(31.4- \\
75.5)\end{array}$ & $\begin{array}{l}54.55(42.4- \\
77.6)\end{array}$ & 0.003 \\
\hline EO(\%) & $0.2(0-0.3)$ & $0.1(0-7.7)$ & $0(0-1.3)$ & $0.1(0-5.7)$ & 0.5803 \\
\hline $\mathrm{BA}(\%)$ & $0.2(0-0.3)$ & $0.2(0-0.4)$ & $0.3(0-0.5)$ & $0.2(0-0.3)$ & 0.6258 \\
\hline 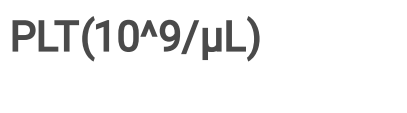 & $683(2,4-910)$ & $764(675-875)$ & $\begin{array}{l}623(418- \\
1395)\end{array}$ & $\begin{array}{l}647(51- \\
856)\end{array}$ & 0,3103 \\
\hline GLUCOSE(mg/dL) & $\begin{array}{l}114(49- \\
170)\end{array}$ & $78(62-132)$ & $32(12-151)$ & $\begin{array}{l}62.5(32- \\
114)\end{array}$ & 0.1485 \\
\hline BUN(mg/dL) & $\begin{array}{l}18.63(12.06- \\
4.17)\end{array}$ & $\begin{array}{l}14.82^{\text {b.c }}(12.75- \\
16.04)\end{array}$ & $\begin{array}{l}67.32(12.89- \\
22.09)\end{array}$ & $\begin{array}{l}49.65(12.94- \\
08.52)\end{array}$ & 0.0307 \\
\hline CREATININE(mg/dL) & $\begin{array}{l}0.54^{\mathrm{a}} \\
0.63)\end{array}(0.47-$ & $\begin{array}{l}0.45^{\text {b.c }} \\
0.51)\end{array}(0.42-$ & $\begin{array}{l}0.69(0.49- \\
1.24)\end{array}$ & $\begin{array}{l}0.54(0.45- \\
0.92)\end{array}$ & 0.0013 \\
\hline AST(U/L) & $\begin{array}{l}23.8^{\mathrm{b}}(18.9- \\
65.3)\end{array}$ & $\begin{array}{l}44.3(26.9- \\
71.8)\end{array}$ & $\begin{array}{l}70.6(22.0- \\
177.3)\end{array}$ & $\begin{array}{l}47.1(16.7- \\
72.3)\end{array}$ & 0.0388 \\
\hline ALT(U/L) & $40^{\mathrm{b}}(27-82)$ & $51^{\mathrm{b}}(39-83)$ & $\begin{array}{l}197(28- \\
1060)\end{array}$ & $\begin{array}{l}127(24- \\
287)\end{array}$ & 0.0339 \\
\hline LDH(U/L) & $\begin{array}{l}186.8^{\mathrm{b}} \\
(171.0-258.8)\end{array}$ & $\begin{array}{l}190.2^{\mathrm{b}}(110.8- \\
274.6)\end{array}$ & $\begin{array}{l}332.5(166.4- \\
332.5)\end{array}$ & $\begin{array}{l}247.9(147.9- \\
332.5)\end{array}$ & 0.0213 \\
\hline $\begin{array}{l}\text { Results are expressed } \\
\text { a: } P<0.05 \text { versus } P c E\end{array}$ & \multicolumn{3}{|c|}{ Results are expressed as median (min-max). $\mathrm{n}=8$. } & 1 & \\
\hline
\end{tabular}

A significant increase was detected in only OSI from TOS, TAS and OSI levels in CLP group, compared with the Sham group $(P<0.05)$, but no significant difference in any parameter was observed between CLP and PcE + CLP groups (Table 2). 
Table 2

Comparison of the tissue TAS,TOS and OSI among the study groups in the intestinal tissue

\begin{tabular}{|c|c|c|c|c|c|}
\hline \multirow[t]{2}{*}{ Parameters } & \multicolumn{5}{|l|}{ Groups } \\
\hline & Sham & PcE & CLP & $\mathrm{PcE}+\mathrm{CLP}$ & $\begin{array}{l}\text { p- } \\
\text { value }\end{array}$ \\
\hline TAS (Trolox Eq/L) & $\begin{array}{l}0.94(0.79- \\
1.08)\end{array}$ & $\begin{array}{l}0.95(0.78- \\
1.12)\end{array}$ & $\begin{array}{l}0.91(0.83- \\
1.14)\end{array}$ & $\begin{array}{l}1.05(0.95- \\
1.17)\end{array}$ & 0.0654 \\
\hline $\begin{array}{l}\text { TOS( }(\mu \mathrm{molH} 2 \mathrm{O} 2 \\
\mathrm{Eqv} / \mathrm{L})\end{array}$ & $\begin{array}{l}5.43(4.3- \\
5.85)\end{array}$ & $\begin{array}{l}8.46(5.35- \\
12.61)\end{array}$ & $\begin{array}{l}8.46(5.35- \\
10.5)\end{array}$ & $8.31(5-11.98)$ & 0.0575 \\
\hline OSI (Arbitrary unit) & $\begin{array}{l}5.52 \\
6.45)\end{array}$ & $\begin{array}{l}8.19(4.96- \\
10.98)\end{array}$ & $\begin{array}{l}8.89^{b}(6.06- \\
5.01)\end{array}$ & $\begin{array}{l}7.38(4.29- \\
12.55)\end{array}$ & 0.0405 \\
\hline
\end{tabular}

Table 3

Histopathological score findings

\begin{tabular}{|lll|}
\hline Groups $(\mathrm{n}=8)$ & İnfiltration & Epitelial damage \\
\hline Sham & $0.0(0.0-1.0)$ & $0.0(0.0-2.0)$ \\
\hline PcE & $0.0(0.0-1.0)$ & $0.0(0.0-2.0)$ \\
CLP & $0.0(0.0-3.0)^{\mathrm{a}}$ & $0.0(0.0-3.0)^{\mathrm{a}}$ \\
\hline PcE + CLP & $0.0(0.0-2.0)^{\mathrm{b}}$ & $0.0(0.0-3.0)$ \\
\hline Results are expressed as median (min-max). $\mathrm{n}=8$. \\
\hline a $\mathrm{P}<0.05$ versus Sham group. ${ }^{\mathrm{b}} \mathrm{P}<0.05$ versus CLP group. \\
\hline
\end{tabular}

\section{Histology}

The Sham and PcE groups exhibited normal histological appearance of the intestinal mucosa except for slight epithelial spillage and infiltration observed in a few sections (Fig. 1A, B and D, E). It was determined that crypta lengths is $166.25 \pm 36.02 \mu \mathrm{m}$ in the Sham group, and is $165.90 \pm 37.49 \mu \mathrm{m}$ in the PcE group; that villus lengths is $260.52 \pm 50.05 \mu \mathrm{m}$ in the Sham group, and is $281.55 \pm 42.46 \mu \mathrm{m}$ in the PcE group. Paneth cells were noted for the presence of densely packed eosinophilic granules in the Sham and PcE groups (Fig. 1C, F).

It was found that the severity of epithelial spillage and infiltration increased in the CLP group and this increase was statistically significant when compared with the Sham group $(p<0.05)$ (Fig. 2A, B). In this group, the mean length of the crypta $(147.05 \pm 36.41 \mu \mathrm{m})$ and the length of the villus $(237.13 \pm 49.70 \mu \mathrm{m})$ were also found to be significantly reduced compared to the Sham group $(p<0.05)$. It was also noted that 
in the CLP group, Paneth cells had a hypertrophic appearance and the granule content in their cytoplasm was significantly reduced compared to the Sham group ( $p<0.05)$ (Fig. 2C)(Table 4).

Table 4

Average crypt debth, villi length ( $\mathrm{AM} \pm \mathrm{SD}$ ), the severity of caspase -3 immunoreactivity and Paneth cell degranulation severity in each group.

\begin{tabular}{|lllll|}
\hline $\begin{array}{l}\text { Groups(n) } \\
=8)\end{array}$ & $\begin{array}{l}\text { Crypt debth } \\
(\mu \mathrm{m})\end{array}$ & $\begin{array}{l}\text { Villi length } \\
(\mu \mathrm{m})\end{array}$ & $\begin{array}{c}\text { Caspase-3 } \\
\text { immunoreactivity }\end{array}$ & $\begin{array}{l}\text { Paneth cell degranulation } \\
\text { severity }\end{array}$ \\
\hline Sham & $\begin{array}{l}166.25 \pm \\
36.02\end{array}$ & $\begin{array}{l}260.52 \pm \\
50.05\end{array}$ & $6.0(2.0-12.0)$ & $1.0(0.0-3.0)$ \\
\hline PcE & $\begin{array}{l}165.90 \pm \\
37.49\end{array}$ & $\begin{array}{l}281.55 \pm \\
42.46\end{array}$ & $6.0(2.0-12.0)$ & $0.0(0.0-3.0)$ \\
\hline CLP & $\begin{array}{l}147.05 \pm \\
36.41^{\mathrm{a}}\end{array}$ & $\begin{array}{l}237.13 \pm \\
49.70^{\mathrm{a}}\end{array}$ & $3.0(1.0-12.0)^{\mathrm{a}}$ & $2.0(0.0-3.0)^{\mathrm{a}}$ \\
\hline PcE + CLP & $\begin{array}{l}175.02 \pm \\
34.33^{\mathrm{b}}\end{array}$ & $\begin{array}{l}264.61 \pm \\
49.84^{\mathrm{b}}\end{array}$ & $6.0(2.0-12.0)^{\mathrm{b}}$ & $1.0(0.0-3.0)^{\mathrm{b}}$ \\
\hline AM \pm SD: arithmetic mean \pm standard deviation & \\
\hline Results are expressed as median (min-max). $\mathrm{n}=8$. & \\
\hline aP $<0.05$ versus Sham group. ${ }^{\mathrm{b}} \mathrm{P}<0.05$ versus group CLP. \\
\hline
\end{tabular}

The severity of infiltration decreased significantly in the PCE + CLP group compared to the CLP group ( $p<$ 0.05) however, it was observed that epithelial spillage continued similar to CLP group (Fig. 2D, E). In this group, it was determined that the length of the crypta $(175.02 \pm 34.33 \mu \mathrm{m})$ and the length of the villus $(264.61 \pm 49.84 \mu \mathrm{m})$ were statistically significantly higher when compared to the CLP group $(p<0.05)$. It was observed that there was a significant decrease in the severity of Paneth cell degranulation in the PcE + CLP group compared to the CLP group, and the appearance of Paneth cells was similar to the control group ( $p<0.05)$ (Fig. 2F, Table 4).

\section{Immunohistochemistry}

Caspase-3 immunoreactivity was observed in surface and gland epithelial cells. The intensity of caspase3 immunoreactivity was similar in the Sham and PcE groups (Fig. 3A, B). To the contrary, we found decreased severity of caspase-3 immunoreactivity in the CLP group compared to the sham group ( $p=$ 0.001) (Fig. 3C). The intensity of caspase-3 immunoreactivity in epithelial cells was significantly increased in PcE + CLP group compared to the CLP group ( $p=0.001)$ (Fig. 3D). Caspase 3 expression is summarized in Table 4.

\section{Discussion}


Sepsis is a complex, destructive condition accompanied by high mortality and limited treatment options. Despite improved surgical techniques and intensive care treatments, sepsis-related mortality rates remain high and continue to be a significant cause of hospital deaths [18-20]. For all these reasons, new and effective treatment methods for sepsis are of great importance.

Multiple organ failure is the usual cause of death from sepsis. Lysosomal enzymes and free oxygen radicals, especially released by neutrophils, participate in the pathogenesis of organ failure [21]. Various antioxidants have been used to prevent accumulation of free oxygen radicals, which participate in mortality due to sepsis.

Extracts of Petroselinum crispum in vitro and in vivo have been reported to possess antioxidant properties [22, 23]; we have found no report of its protective effects against sepsis.

We used CLP induced sepsis as our model. Sepsis was verified by hemogram (neutrophils, lymphocytes), biochemical (AST, ALT, LDH, BUN, TAS, TOS and OSI levels) and histopathological changes, which are used to confirm sepsis In the comparison between Sham and CLP groups, the increase in the OSI level means that CLP increases oxidative stress, while its decrease between CLP and PcE + CLP groups means that PcE reduces sepsis induced oxidative stress.

We found a significant decrease in TAS in the intestinal tissue extracts It is described in Methods Even though the decrease in TAS level in CLP group according to Sham group, the increase in PcE + CLP group according to CLP group was not statistically significant, it was significant in that it showed that CLP induced sepsis while PcE reduced it. Previous studies have shown that antioxidant markers are diminished in sepsis via CLP. In a study by Ritter et al., It was demonstrated that antioxidant enzymes such as catalase and superoxide dismutase activity were reduced in essential organs involved in the septic response [24]. [25] reported the increase of glutathione level of parsley extract. With this result, it was concluded that parsley extract had a protective effect due to its antioxidant properties. All of these previous studies show that sepsis increases oxidative stress and the antioxidant system decreases. In the present study, this situation was shown with the change in TOS, OSI and TAS levels. We did not show them one by one, but as oxidative stress markers (TOS, OSI) and antioxidant markers (TAS).

The oxygen-free radicals containing malondialdehyde (MDA), hydrogen peroxide and hydroxyl radicals cause peroxidative stress. Reduced antioxidative defenses, such as superoxide dismutase, catalase, and glutathione (GSH), also contribute to oxidative stress. Then, organ failure occurs [26]. In this study, it was observed that parsley extract had a protective effect against CLP, with biochemical and histopathological analyzes showing that it reduces multi-organ damage. This protective effect is primarily due to the inhibition of oxidative stress, which is one of the most important mechanisms of organ injury in sepsis. In our current study, it has been proven that the administration of parsley extract before CLP-induced sepsis increases neutrophil, PLT counts and TAS levels which decrease with sepsis and decreases biochemical changes (BUN, AST, ALT, LDH, TOS, OSI) which increase with sepsis, to have a protective effect on sepsis . 
Histopathological changes that were determined that epithelial damage and infiltration severity increased, crypt-villus length, Paneth cell hypertrophy, and its cytoplasm granules decreased in the CLP group supported sepsis syndrome. These changes have been confirmed by previous studies [27]. The intestinal histological changes, including significantly reduced of the severity of infiltration, were reversed by the use of PcE. This situation showed us the protective effect of PcE on intestinal mucosa in sepsis. In the current study, we evaluated apoptosis by caspase-3 activity. Caspase- 3 activity decreased significantly in the CLP group compared to the Sham group and a significant increase in PcE + CLP groups compared to the CLP group can be interpreted as parsley extract has apoptosis-inducing activities and protective effects. The histopathological and biochemical results obtained in this study were similar to previous studies $[28,29]$.

As shown in previous studies, in this study, the decrease in the TOS and OSI levels, as well as their histopathological changes such as especially a reduction of intestinal infiltration, were demonstrated the antioxidant properties of PCE $[30,31]$. In further research, we think that the content of parsley extract will be elucidated in more detail by chromatographic methods, and the active substances or plant-prepared bioactive fractions isolated from the plant will offer alternative treatment options.

As result, especially in hospitalized patients or other patients at risk for sepsis; we believe that our research may be the first step for a drug that can be developed to reduce the risk of sepsis and facilitate the treatment.

\section{Declarations}

\section{Ethics approval}

The Ethics Committee for Experimental Animal Research approved our study (Reference no.2015/A-34)

\section{Consent for publication}

Publishing consent granted by the authors

\section{Availability of data and materials}

Data and materials can be provided upon request by corresponding author.

\section{Funding}

Grants under the 2209 program, The Scientific and Technological Research Council of Turkey, supported this study financially.

\section{Author information}

\section{Affiliations}


Inonu University, Faculty of Medicine, Department of Gastroenterology AD, Malatya, Turkey

Yasir Furkan Cagin

Istanbul University, Capa, Faculty of Medicine, Department of Microbiology, Istanbul, Turkey

Ihsan Kulaksiz

Inonu University, Faculty of Medicine, Department of Histology and Embryology, Malatya, Turkey

Nigar Vardi, Azibe Yildiz

Inonu University, Faculty of Medicine, Department of Medical Pharmacology, Malatya, Turkey

Hakan Parlakpinar

Inonu University, Faculty of Medicine, Department of Physiology, Malatya, Turkey

Alaadin Polat, Kevser Tanbek

Inonu University, Faculty of Medicine, Department of Biostatistics and Medical Informatics, Malatya, Turkey

Ahmet Kadir Arslan

\section{Contributions}

Y.F.C. Conceiving and designing the study, writing the article, analysis, interpretation of data and performed the other procedures, I.K. acquisition of data and design its, N.V. and A.Y. the histopathological evaluations, H.P. providing critical revisions that are important for the intellectual content, approving the final version of the manuscript and performed the surgical procedures, 0.0 . acquisition of data and design its, A.P. and K.T. the biochemical analysis, A.K.A. the statistical analysis. All authors contributed to the manuscript's draft.

Corresponding author

Correspondence to Yasir Furkan Cagin.

\section{Ethics declarations}

Conflict of Interest

The authors declare that they have no conflict of interest.

\section{References}


1. Neviere, R., P. E. Parsons, and G. Finlay. 2017. Sepsis syndromes in adults: Epidemiology, definitions, clinical presentation, diagnosis, and prognosis. Monografía en Internet]. Wolters Kluwer: UpToDate..

2. Martin, G. S., D. M. Mannino, S. Eaton, and M. Moss. 2003. The epidemiology of sepsis in the United States from 1979 through 2000. New England Journal of Medicine 348: 1546-1554. DOI:10.1056/NEJMoa022139.

3. Zhou, L., M. Gao, Z. Xiao, J. Zhang, X. Li, and A. Wang. 2015. Protective effect of astaxanthin against multiple organ injury in a rat model of sepsis. Journal of Surgical research 195: 559-567. https://doi.org/10.1016/j.jss.2015.02.026.

4. Bone, R. C. 1991. The pathogenesis of sepsis. Annals of internal medicine 115: 457-469. DOI:10.7326/0003-4819-115-6-457.

5. Cohen, J. 2002. The immunopathogenesis of sepsis. Nature 420: 885. DOI:10.1038/nature01326.

6. Hubbard, W. J., M. Choudhry, M. G. Schwacha, J. D. Kerby, L. W. Rue III, K. I. Bland, and I. H. Chaudry. 2005. Cecal ligation and puncture. Shock (Augusta, Ga.) 24: 52-57. doi:10.1097/01.shk.0000191414.94461.7e.

7. Walley, K. R., N. W. Lukacs, T. J. Standiford, R. M. Strieter, and S. L. Kunkel. 1996. Balance of inflammatory cytokines related to severity and mortality of murine sepsis. Infection and immunity 64: 4733-4738. DOI:10.1128/iai.64.11.4733-4738.1996.

8. Farzaei, M. H., Z. Abbasabadi, M. R. S. Ardekani, R. Rahimi, and F. Farzaei. 2013. Parsley: a review of ethnopharmacology, phytochemistry and biological activities. Journal of traditional Chinese medicine 33: 815-826. DOI:10.1016/s0254-6272(14)60018-2.

9. Wong, P. Y., and D. D. Kitts. 2006. Studies on the dual antioxidant and antibacterial properties of parsley (Petroselinum crispum) and cilantro (Coriandrum sativum) extracts. Food chemistry 97: 505-515. https://doi.org/10.1016/j.foodchem.2005.05.031.

10. Toscano, M. G., D. Ganea, and A. M. Gamero. 2011. Cecal ligation puncture procedure. Journal of visualized experiments: JoVE. doi: 10.3791/2860.

11. Erel, O. 2004. A novel automated method to measure total antioxidant response against potent free radical reactions. Clinical biochemistry 37: 112-119. https://doi.org/10.1016/j.clinbiochem.2003.10.014.

12. Erel, O. 2004. A novel automated direct measurement method for total antioxidant capacity using a new generation, more stable ABTS radical cation. Clin Biochem 37: 277-285. doi:10.1016/j.clinbiochem.2003.11.015.

13. Erel, O. 2005. A new automated colorimetric method for measuring total oxidant status. Clin Biochem 38: 1103-1111. doi:10.1016/j.clinbiochem.2005.08.008.

14. Bancroft, J. D., and M. Gamble. 2008. Theory and practice of histological techniques. Elsevier health sciences.

15. Taslidere, E., N. Vardi, H. Parlakpinar, A. Yıldız, B. Taslidere, and M. Karaaslan. 2018. Effects of melatonin on acetylsalicylic acid induced gastroduodenal and jejunal mucosal injury. Biotechnic \& Histochemistry 93: 485-495. DOI:10.1080/10520295.2018.1442020. 
16. Adolph, T. E., M. F. Tomczak, L. Niederreiter, H.-J. Ko, J. Böck, E. Martinez-Naves, J. N. Glickman, M. Tschurtschenthaler, J. Hartwig, and S. Hosomi. 2013. Paneth cells as a site of origin for intestinal inflammation. Nature 503: 272-276. doi:10.1038/nature12599.

17. Parlakpinar, H., O. Ozhan, N. Ermis, N. Vardi, Y. Cigremis, L. H. Tanriverdi, C. Colak, and A. Acet. 2019. Acute and subacute effects of low versus high doses of standardized Panax ginseng extract on the heart: an experimental study. Cardiovascular toxicology 19: 306-320. DOI:10.1007/s12012-01909512-1.

18. Rodríguez, F., L. Barrera, G. De La Rosa, R. Dennis, C. Dueñas, M. Granados, D. Londoño, F. Molina, G. Ortiz, and F. Jaimes. 2011. The epidemiology of sepsis in Colombia: a prospective multicenter cohort study in ten university hospitals. Critical care medicine 39: 1675-1682. doi:10.1097/CCM.0b013e318218a35e.

19. Iwashyna, T. J., G. Netzer, K. M. Langa, and C. Cigolle. 2012. Spurious inferences about long-term outcomes: the case of severe sepsis and geriatric conditions. American journal of respiratory and critical care medicine 185: 835-841. https://doi.org/10.1164/rccm.201109-16600C.

20. Jones, A. E., M. D. Brown, S. Trzeciak, N. I. Shapiro, J. S. Garrett, A. C. Heffner, and J. A. Kline. 2008. The effect of a quantitative resuscitation strategy on mortality in patients with sepsis: a metaanalysis. Critical care medicine 36: 2734. doi:10.1097/CCM.0b013e318186f839.

21. Reinhart, K., F. Bloos, and F. Brunkhorst. 2005. Pathophysiology of sepsis and multiple organ dysfunction. Textbook of Critical Care. Eds: Fink MP, Abraham E, Vincent JL, Kochanek PM. Fifth edition. Elsevier-Saunders, Philadelphia:1249-1258.

22. Popović, M., B. Kaurinović, V. Jakovljević, N. Mimica-Dukic, and M. Bursać. 2007. Effect of parsley (Petroselinum crispum (Mill.) Nym. ex AW Hill, Apiaceae) extracts on some biochemical parameters of oxidative stress in mice treated with CCl4. Phytotherapy research 21: 717-723. doi:10.1002/ptr.2134.

23. Zhang, H., F. Chen, X. Wang, and H.-Y. Yao. 2006. Evaluation of antioxidant activity of parsley (Petroselinum crispum) essential oil and identification of its antioxidant constituents. Food research internationa/39: 833-839. https://doi.org/10.1016/j.foodres.2006.03.007.

24. Ritter, C., M. E. Andrades, A. Reinke, S. Menna-Barreto, J. C. F. Moreira, and F. Dal-Pizzol. 2004. Treatment with $\mathrm{N}$-acetylcysteine plus deferoxamine protects rats against oxidative stress and improves survival in sepsis. Critical care medicine 32: 342-349. doi:10.1097/01.CCM.0000109454.13145.CA.

25. Ozsoy-Sacan, O., R. Yanardag, H. Orak, Y. Ozgey, A. Yarat, and T. Tunali. 2006. Effects of parsley (Petroselinum crispum) extract versus glibornuride on the liver of streptozotocin-induced diabetic rats. Journal of ethnopharmacology 104: 175-181. https://doi.org/10.1016/j.jep.2005.08.069.

26. Koksal, G., C. Sayilgan, S. Aydin, H. Oz, and H. Uzun. 2004. Correlation of plasma and tissue oxidative stresses in intra-abdominal sepsis. Journal of Surgical Research 122: 180-183. https://doi.org/10.1016/j.jss.2004.07.246. 
27. Leng, Y., K. Zhang, J. Fan, M. Yi, Q. Ge, L. Chen, L. Zhang, and G. Yao. 2014. Effect of acute, slightly increased intra-abdominal pressure on intestinal permeability and oxidative stress in a rat model. PloS one 9: e109350. https://doi.org/10.1371/journal.pone.0109350.

28. Shukla, S., and S. Gupta. 2010. Apigenin: a promising molecule for cancer prevention. Pharmaceutical research 27: 962-978. DOI:10.1007/s11095-010-0089-7.

29. Sęczyk, Ł, M. Świeca, U. Gawlik-Dziki, M. Luty, and J. Czyż. 2016. Effect of fortification with parsley (Petroselinum crispum Mill.) leaves on the nutraceutical and nutritional quality of wheat pasta. Food chemistry 190: 419-428. https://doi.org/10.1016/j.foodchem.2015.05.110.

30. Al-Juhaimi, F., and K. Ghafoor. 2011. Total phenols and antioxidant activities of leaf and stem extracts from coriander, mint and parsley grown in Saudi Arabia. Pakistan Journal of Botany 43: 2235-2237.

31. Fejes S, Blazovics A, Lemberkovics E, Petri G, Szöke E and Kery A (2000) Free radical scavenging and membrane protective effects of methanol extracts fromAnthriscus cerefolium L.(Hoffm.) andPetroselinum crispum (Mill.) Nym. ex AW Hill. Phytotherapy Research 14:362-365. doi: 10.1002/1099-1573(200008)14:5<362::aid-ptr554>3.0.co;2-g.

\section{Figures}

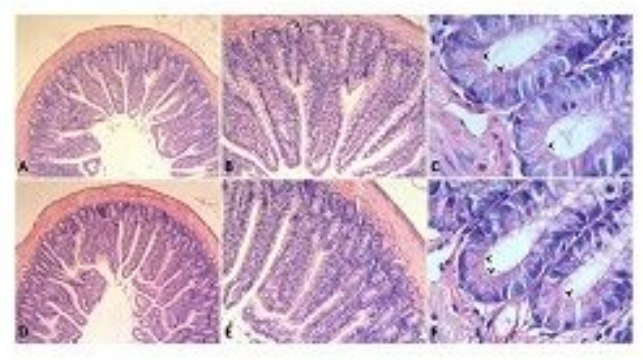

\section{Figure 1}

Paneth cells characterized by eosinophilic granules located in the basal of the intestinal tissue and crypts in normal histological appearance in the Sham (A; 10x, B; 20x, C; 100x) and PcE (D; 10x, E; 20x, F; 100x) groups. Arrowheads indicate Paneth cells. 


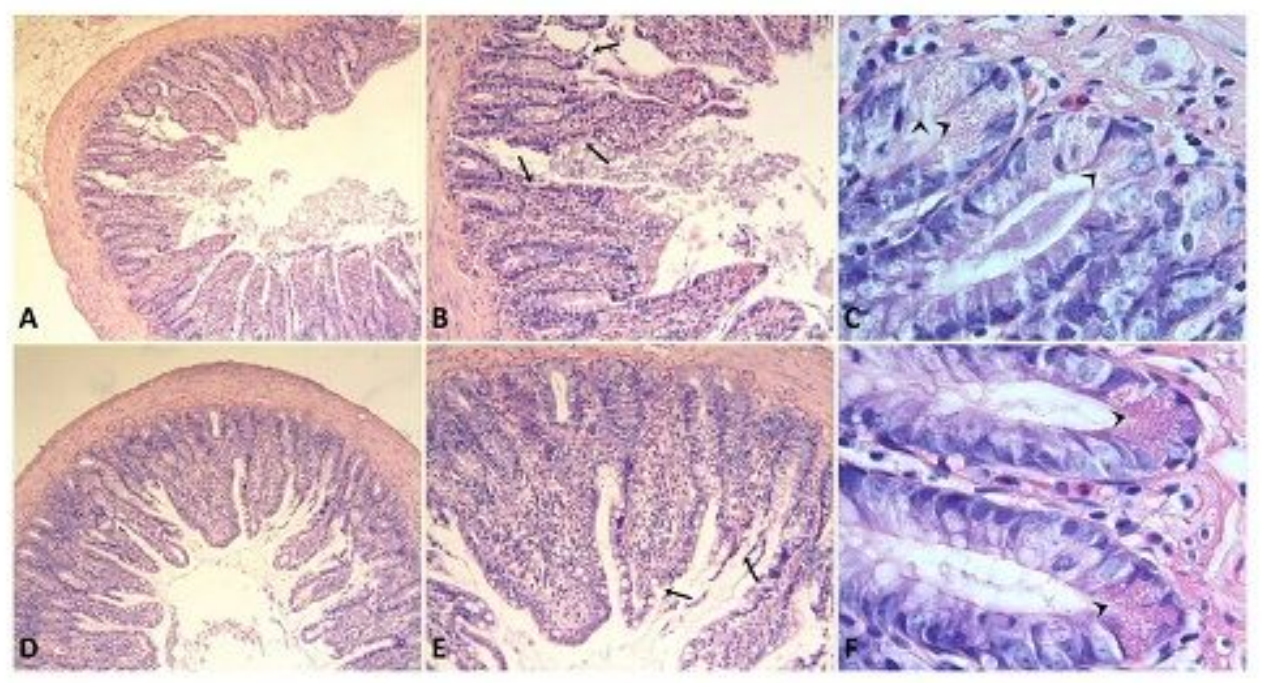

\section{Figure 2}

Appearance of villus and crypts and Paneth cells in the CLP (A; 10x, B; 20x, C; 100x) and PcE + CLP (D; 10x, E; 20x, F; 100x) groups. Arrows indicate the epithelial damage, arrowheads Paneth cells.

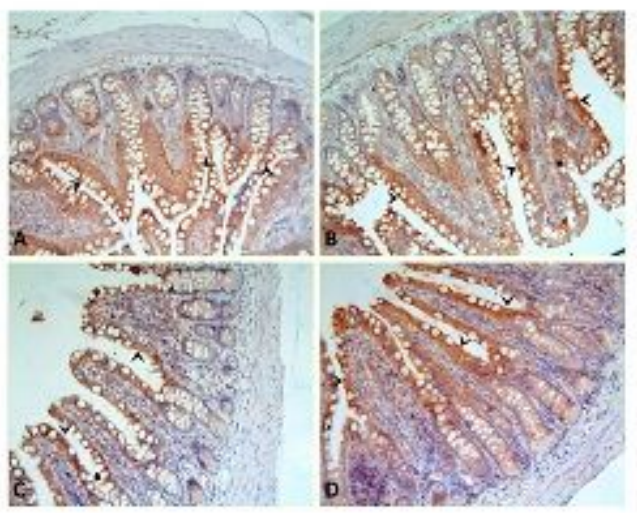

\section{Figure 3}

Similar caspase-3 immunoreactivity is observed in the Sham (A) and PcE (B) groups. In CLP group (C), decrease in caspase-3 immunoreactivity is showed. On the other hand, significant increase in caspase-3 immunoreactivity is noted with PcE treatment (D). Caspase-3 immunostaining; magnification x20. 